\title{
Signs and symptoms of temporomandibular disorder and patients' satisfaction before and after orthognathic surgery
}

\author{
Edmar Ricardo Pozzobon Christovam¹, Eloisa Marcantonio Boeck², Silvia Amélia Scudeler Vedovello1, \\ Heloisa Cristina Valdrighi', Viviane Veroni Degan', Mário Vedovello Filho' \\ ${ }^{1}$ Fundação Hermínio Ometo - FHO/UNIARARAS, School of Dentistry, Department of Orthodontics, Araras, SP, Brazil \\ 'Universidade de Araraquara- UNIARA, Centro Universitário de Araraquara, School of Dentistry, Department of Orthodontics, Araraquara, SP, Brazil
}

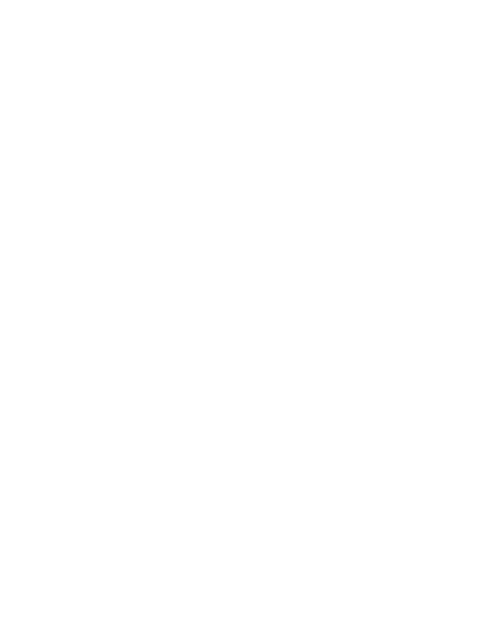

\begin{abstract}
Aim: To evaluate signs and symptoms of temporomandibular joint disorder and satisfaction in patients before and after orthognathic surgery. Methods: The sample consisted of 15 patients aged between 19 and 47 years old, indicated for orthodontic-surgical treatment. All patients answered an anamnesis questionnaire based on Helkimo Anamnestic Index to evaluate subjective symptoms and underwent a clinical evaluation based on Helkimo Disfunction Index, applied at three time points: before (T0), three (T1) and six months (T2) after surgery. Statistical models used were $\chi^{2}$ test (Chi-square), Tukey test, confidence interval and analysis of variance (ANOVA). Results: Statistical analysis revealed no significant difference in the incidence of joint sounds, maximum mouth opening, deviation of mouth opening and pain in the TMJ region ( $p>0.05)$. No patient presented worsening of the symptomatology. As regards muscular pain, there was a statistically significant improvement with time $(p<0.05)$ and $86.7 \%$ of patients reported that they were satisfied with the obtained results. Conclusions: Improvement of TMD after orthognathic surgery may not be the result of correcting malocclusion and satisfaction with the results can be a factor of TMD improvement.
\end{abstract}

Keywords: Orthodontics. Temporomandibular Joint. Malocclusion. Self-concept.

\section{Introduction}

Surgical correction of dentofacial deformities is recommended to improve facial esthetics and social relationships, to establish static and functional occlusion health, stable results ${ }^{1,2}$ and adaptation of temporomandibular joint (TMJ) ${ }^{3}$. The psychosocial impact of a dentofacial deformity may alter an entire lifestyle and be critical for self-esteem due to the psychological effects caused by facial and dental appearance ${ }^{1}$.

The prime importance of stable results in orthognathic surgery is TMJ health. If

Received for publication: June 26, 2016 Accepted: October 27, 2016

Correspondence to: Edmar Ricardo Pozzobon Christovam Fundação Hermínio Ometo - FHO/UNIARARAS, Curso de Odontologia Av. Maximiliano Baruto, 500 - Jd. Universitário, CEP: 13607-339 - Araras -SP, Brasil Phone: +55-19-3861-0472. Fax: +55-19-3861-0178

E-mail: edmarchristovam@ortodontista.com.br the TMJ is not in good condition, the surgical outcome procedure may be unsatisfactory in terms of function, aesthetics, stability and pain; and any type of pain or dysfunction must be assessed before performing an orthognathic surgery ${ }^{4}$. Some patients with open bite or large incisors overlap should be viewed as a risk factor before starting orthodontic, prosthodontic, routine oral surgery (third molar extraction) or orthognathic surgery, because these skeletal features may suggest an increase in mandibular pain and dysfunction after treatment ${ }^{5}$. Anyway, a previous evaluation is important to properly identify these signs and symptoms while planning an orthognathic surgery ${ }^{6}$.

There are controversies concerning the adequate procedure in patients with preexistent temporomandibular disorder (TMD) that need orthodontic-surgical treatment 
to correct dentofacial deformities. There are two distinct theories: one states that surgical procedures can reduce TMJ dysfunction's symptoms ${ }^{7}$, while other asserts that orthognathic surgery causes future deleterious effects on TMJ and worsens the dysfunction's symptoms ${ }^{8}$.

Signs and symptoms, consisting of TMJ pain, pain in masticatory muscles, headache, limited mouth opening and joint noise may define $\mathrm{TMD}^{5,9}$.

Helkimo $^{10}$ (1974), with the aim of facilitating both scientific investigations and patients routine exams with different types of symptoms and severity degrees, suggested a method comparing signs and symptoms of TMD. The patients were submitted to a clinical masticatory system dysfunction evaluation, an anamnesis interview and occlusion evaluation. Data were collected and a numerical classification of the prevailing type was established, determining three indexes: Clinical Dysfunction Index, Anamnestic Dysfunction Index and Index for Occlusal State. From then on, several authors ${ }^{11-15}$ have studied the subject based on Helkimo's work.

Onizawa et al. ${ }^{8}$ (1995) investigated TMJ alterations at three and six months after orthognathic surgery, comparing patients who underwent orthognatic surgery with patients who did not. They concluded that the joint symptoms alterations after surgery are not always the result of correcting malocclusion, but in practice due to factors like the influence of the orthognathic surgery on the masticatory muscles.

Gaggl et al. ${ }^{16}$ (1999) reported that the major problem faced by oral and maxillofacial surgeons is not only placing the bone bases into esthetic and ideal functional positions, but also repositioning bone bases in a way that TMJ is restablished in a physiological manner. Using magnetic resonance preoperatively and 3 months after orthognathic surgery and clinical data like maximum mouth opening, presence of joint sounds and palpation of masticatory muscles, the authors concluded that clinical findings combined with the magnetic resonance images supported that, in many cases, clinical improvement of signs and symptoms of TMD are acceptable after correcting joint complex position in orthodontic-surgical treatment.

There are patient variations regarding psychological and physiological surgery effects ${ }^{6}$, and the risk of developing TMD in orthognathic patients has been attributed to various factors including psychological distress ${ }^{17,18}$.

Orthognathic surgery presents an interesting model to study pain and function of the masticatory system ${ }^{19}$. Investigating TMD signs and symptom characteristics and post-operative changes in orthognathic patients leads to a better understanding of orthognathic surgery influence on $\mathrm{TMD}^{7}$.

This study aimed to evaluate signs and symptoms of TMD in patients before and after orthognathic surgery and their satisfaction after orthodontic surgical treatment.

\section{Material and methods}

The research was developed after approval of the Research Project by the Research Ethics and Merit Committee (protocol number 763/2007). The sample was selected at Center of
Research and Treatment of Orofacial Deformities (CEDEFACE) according to the following inclusion criteria: patients with dentofacial deformities referred to orthodontic-surgical treatment, irrespective of facial pattern, with signs and symptoms of TMD, assessed by a questionnaire. The exclusion criteria were: patients who underwent previous treatment of TMJ, or suffered facial traumatism, fissured lip and with ankylosis of the TMJ. Thus, among 20 assessed patients, 15 were selected; 12 were women and 3 were men, aged between 19 and 47 years.

All patients filled out a questionnaire based on Anamnestic disfunction index ${ }^{10}$, to evaluate subjective symptoms, and were also subjected to a clinical examination based on Helkimo's dysfunction index ${ }^{10}$, applied pre-surgical and three and six months post-surgical procedure. The anamnesis questionnaire approached matters concerning sounds in TMJ (clicking and crepitation), confirmed with a stethoscope as suggested by Gaggl et al. ${ }^{16}$ (1999); face pain, by asking the patients to indicate the most sensitive region on a face front view drawing; pain at TMJ region at mouth opening, including mandibular movements and asking the patients to indicate pain intensity using a numerical visual scale suggested by Wolford et al. ${ }^{7}$ (2003), ranging from 1 (pain absence) to 10 (intense pain). At last, the patients were asked if the general pain symptoms after surgery improved, turned worse or had no change.

The clinical examination evaluated mandibular movements as maximal mouth opening, protrusive movement, group function and canine guidance, and muscular pain on palpation. To obtain an average, maximal mouth opening and the range of protrusive movement were measured three times, at the same moment, with a dry tip compass with a locking device, by the interincisal distance and then measured with a millimetric ruler $^{16}$. Group function or canine guidance movements were determined visually. Masticatory muscles were evaluated bilaterally by palpation, by the same examiner, which was performed as follows: the masseter muscle was palpated extraorally from its upper insertion point to the area of the mandibular angle; the temporal muscle was palpated extraorally in the temporal region of the head; the lateral pterygoid muscle was palpated intraorally near the distal, lateral and upper region of the maxillary tuberosity; the medial pterygoid muscle was palpated extraorally behind the mandibular angle and intraorally in the inferior and posterior portion of the lingual groove of the mandible ${ }^{20}$.

Patients were subjected to a mandible or a maxilla surgery and/or a combination of both. For mandible, the used technique was bilateral sagittal osteotomy of mandibular ramus ${ }^{21,22}$, and for maxilla it was the Le Fort I type osteotomy. The mandible proximal segments were positioned manually, without using holding devices for the mandible head. At surgery, acrylic resin interocclusal plates (surgical guides) were used to establish the correct occlusion position until rigid internal fixation procedure with mini-plates and titanium screws was performed. For better stability, the first fixation was on the larger bone contact area, avoiding torsion of the mandibular head. After fixation, new occlusion passivity was checked. During the post-surgical phase, no patient had physical therapy follow-up.

Three and six months after surgery, all data were collected again, and in the last evaluation, patients answered if they were 
satisfied with the results of treatment.

The hypothesis refers to equality comparison between proportions or averages and the statistical models used to verify such hypothesis was the $\chi^{2}$ test (square Chi), analysis of variance (ANOVA), confidence interval and Tukey test.

\section{Results}

It was possible to verify if the results of subjective evaluation, which the study analyzed and compared, showed subsidies to reject the hypothesis that the occurrence of clicking versus time after surgery was independent events (Table 1). Applying the $\chi^{2}$ test there was a significant reduction $(p<0.05)$ in clicking. Similarly, in spite of the reduction of crepitation at the evaluated timepoints, the results were not significant compared with the evaluated total percentage $(p=0.18)$. Regarding face pain (Table 1), most patients pointed on temporal region of the drawing. For statistical analysis, data were divided and the $\chi^{2}$ test was applied, so that on temporal region the presence or absence of pain regardless the time point, presented a significant decrease $(p=0.001)$. The absence of pain showed a smaller number of patients in a given time compared with the consecutive time point, the opposite that occured with the pain. The relevance to assess pain intensity on TMJ region referred to the question: does the degree of pain at initial time, reported by patients based on a visual scale, decrease with time after surgery? This question was assessed using statistical analysis of confidence intervals to 95\% for true average, using only the patients who had pain at the initial time. Thus, the sample was reduced to 9 patients and the statistical analysis showed that the true averages (middle grade), estimated at the three moments, were statistically equal to each other. This is because the confidence intervals of $95 \%$ presented common points, which made us deduce that the degree of pain showed no decrease over time (Figure 1). For general pain symptoms with time, the results showed that no patient experienced worsening of pain he/she felt before surgery, and that despite the pain improvement, this alteration in the time intervals (from T0 to T1 and from T1 to T2) were independent events $(p=0.361)$, calculated by distribution $\chi^{2}$ (square Chi) with one (1) degree of freedom (Figure 2).

Table 1 - Frequency of TMD symptomatology according to time.

\begin{tabular}{|c|c|c|c|c|c|c|c|c|}
\hline \multicolumn{2}{|l|}{ Symptom } & \multicolumn{2}{|c|}{ Initial (T0) } & \multicolumn{2}{|c|}{ After 3 months (T1) } & \multicolumn{2}{|c|}{ After 6 months (T2) } & \multirow{2}{*}{$\begin{array}{c}\text { Total } \\
19(42.2)\end{array}$} \\
\hline Clicking & Presence & 9 & $(60.0)$ & 8 & $(53.3)$ & 2 & $(13.3)$ & \\
\hline \multirow[t]{2}{*}{$(p<0.05)$} & Absence & 6 & $(40.0)$ & 7 & $(46.7)$ & 13 & $(86.7)$ & $26(57.8)$ \\
\hline & Total & 15 & $(100.0)$ & 15 & $(100.0)$ & 15 & $(100.0)$ & $45(100.0)$ \\
\hline Crepitation & Presence & 5 & (33.3) & 4 & $(26.7)$ & 1 & (6.7) & $10(22.2)$ \\
\hline \multirow[t]{2}{*}{$(p>0.05)$} & Absence & 10 & $(66.7)$ & 11 & (73.3) & 14 & $(93.3)$ & $35(77.8)$ \\
\hline & Total & 15 & $(100.0)$ & 15 & $(100.0)$ & 15 & $(100.0)$ & $45(100.0)$ \\
\hline Face pain & Presence & 12 & $(80.0)$ & 3 & $(20.0)$ & 1 & $(6,7)$ & $16(35.6)$ \\
\hline (temporal region) & Absence & 3 & $(20.0)$ & 12 & $(80.0)$ & 14 & $(93.3)$ & $29(64.4)$ \\
\hline$(p<0.05)$ & Total & 15 & $(100.0)$ & 15 & $(100.0)$ & 15 & $(100.0)$ & $45(100.0)$ \\
\hline
\end{tabular}

Absolute frequency: outside of parenthesis/Relative Frequency: inside parenthesis

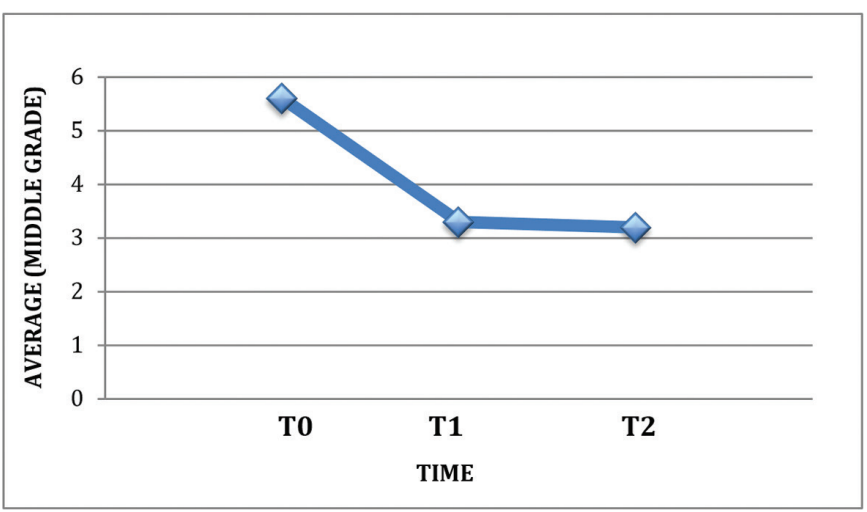

Fig.1. Middle grade of pain intensity on TMJ region according to time. T0 (before surgery); T1 (3 months after surgery); T2 (6 months after surgery).

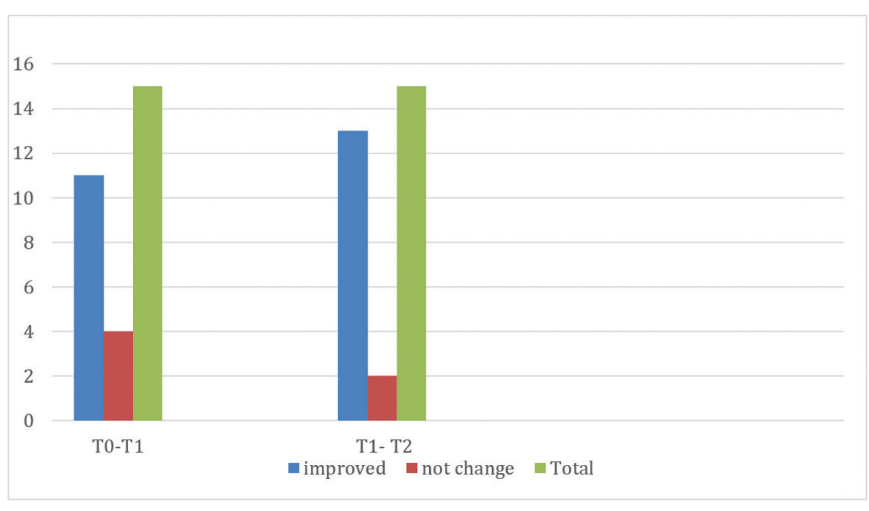

Fig.2. General pain symptoms after surgery. 
Clinical assessment indicated the means of three measurements of mouth opening and protrusive movement that the patient could make when opening his/her mouth as far as possible. They were statistically analyzed using the statistical model of ANOVA at a fixed criterion, which was time, thus verifying that the hypothesis of maximum mouth opening was the same at each time point of surgery. This model provided a meaningful probability $(p=0.0001)$; but additional Tukey test revealed that at three and six month points after surgery, these means were statistically equal and lower than the mean of maximum mouth opening in the initial instant (Figure 3). For the protrusive movement, the application of the ANOVA (Figure 4) model derived a non-meaningful probability $(\mathrm{p}=0.891)$.

Ignoring the datum "unable to do" due to the value under 1 and working only with the data of the canine guidance and group function, it was observed that the canine guidance movement was easier to make along time $(p<0.05)$, while group function movement was more difficult (Table 2).

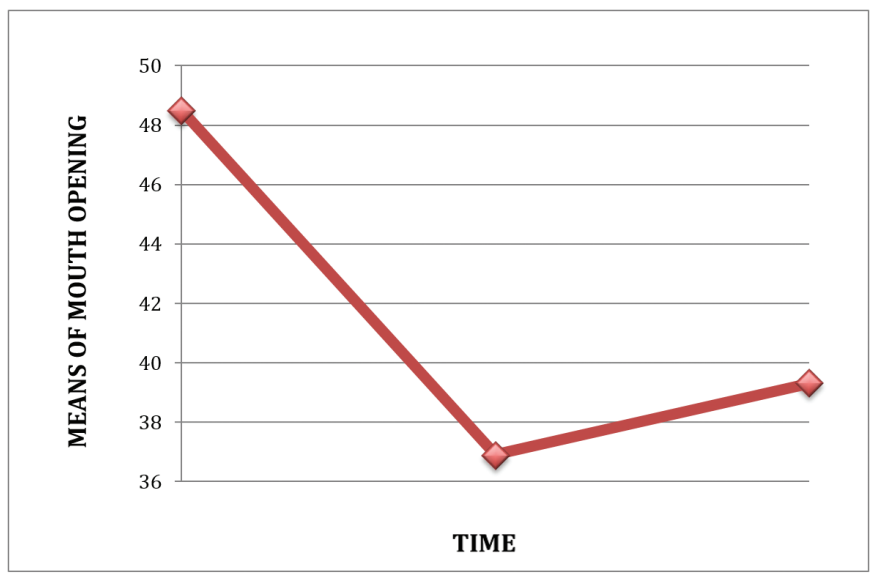

Fig.3. Means of mouth opening according to time.

$0.00=\mathrm{T} 0$ (before surgery); $1.00=\mathrm{T} 1$ ( 3 months after surgery); $2.00=\mathrm{T} 2(6$ months after surgery).

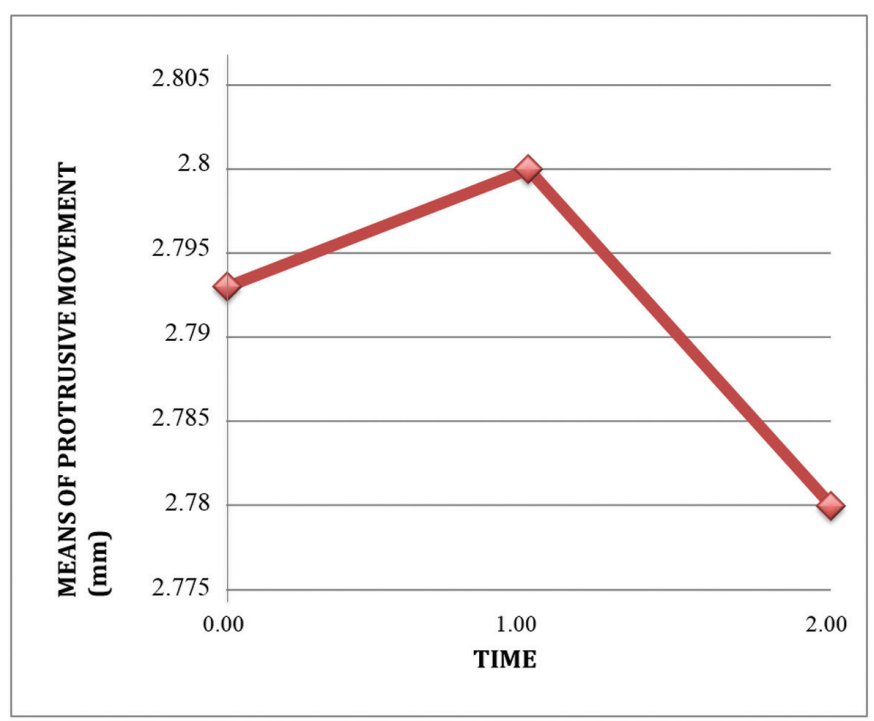

Fig.4. Means of protrusive movement according to time. $0.00=$ T0 (before surgery); $1.00=$ T1 (3 months after surgery); $2.00=\mathrm{T} 2$ (6 months after surgery).
Regarding pain on palpation of masseter muscle, the sample showed subsidies to not reject the hypothesis that the occurrence or not of pain versus time after surgery were independent events $(p=0.36)$ and the meaning of this fact was that the percentage of absent pain in each post-surgery time were statistically equal to the total percentage of the absence of this pain (Table 3), which in this case was $73.3 \%$ implying that those percentages were statistically equal to each other, and the percentage of the pain in each post-surgery time were statistically equal to the total percentage of the presence of this pain, which in this case was $26.7 \%$, implying that those percentages were statistically equal to each other. For temporal muscle (Table 3), the sample showed subsidies to reject the hypothesis that the occurrence or not of pain versus time after surgery were independent events $(p=0.08)$, and the results indicated that with post-surgery time, pain on palpation of this muscle decreased. For lateral pterygoid and medial pterygoid muscles (Table 3), the sample showed subsidies to reject the hypothesis that the occurrence or not of pain versus time after surgery were independent events $(p=0.001$ and $p=0.0004$ respectively).; It was noted that for lateral pterigoyd muscle from time point to three months after surgery, all patients showed absence of pain. For medial pterigoyd muscle the percentage of pain at each time post-surgery was statistically different from the percentage of presence of this pain, which in this case was $20.0 \%$ and at six month time point, all patients had absence of pain on palpation in this muscle.

Six months after surgery (T2) the patients were asked if they were satisfied with the results obtained from orthodonticsurgical treatment. Most of them (86.7\%) declared they were satisfied with the performed surgical procedures, which was statistically significant.

\section{Discussion}

Several studies have been conducted to elucidate TMD relationship with orthognathic surgery ${ }^{11-15,17-20}$. In addition to improve the appearance, an important goal of orthodontic surgical treatment is to improve functional occlusion with masticatory function ${ }^{1}$. Defined as a series of clinical problems that affect masticatory muscles, TMJ and its related structures generally, the etiology of TMD is considered multifactorial and malocclusion does not seem to be a significant etiological factor, but only one of the factors in a complex etiological context ${ }^{8,23}$.

Maximum mouth opening is an indicator of mandibular function ${ }^{24}$ and in the present study there was a significant reduction, which may have been influenced by the post-operative edema ${ }^{16}$. Also protrusive movement means showed no significance over time, maybe because the sample presented negative and positive overjet. This requires further studies with homogenous patient samples of dentofacial deformities and the same TMD ${ }^{24}$. Lateral excursive movements were visually assessed regarding canine guidance or group function and the results showed an improvement on canine guidance after six months Anyway, it was not possible to associate it to reduction of mandibular mobility and clicking. The clicking in the assessments at three and six months after orthognathic surgery had a significant reduction, while the presence 
of crepitation remained unaltered with time. These results may be associated with the significant reduction in maximum mouth opening after surgery, presented by the patients ${ }^{12,13}$ or due to changes in condylar position caused by surgery ${ }^{25}$.

Reduction of painful sensitivity of the masticatory muscles after surgery was an important result of this study, both in the subjective assessment and clinical evaluation by means of muscular palpation ${ }^{13,25}$. On the other hand, some studies did not observe any change in muscular pain symptomatology with time, leading to conclusion that orthognathic surgery did not influence the relief of muscular pain and that improvement in TMD was unpredictable ${ }^{11,12,19}$, requiring follow up of the symptoms for several years ${ }^{8}$ and independent treatment ${ }^{11}$.

TMD must be carefully assessed before orthognathic surgery in patients who have clear dysfunction signs and symptoms as well in those who are completely asymptomatic ${ }^{5,8}$. Patients with TMD before the orthognathic surgery tended to have significant increase in dysfunction signs and symptoms ${ }^{7,24,26}$. Contrarily, evaluating before and after orthognatic surgery, the results of this study showed that patients with previous TMD signs and symptoms, regardless of time, had significant improvement of subjective and clinical TMD signs and symptoms $s^{7,13,15,17,26-29}$ and no patient presented worsening symptoms after orthognathic surgery. Therefore, the improvement of the signs or symptoms of TMD after orthodontic-surgical treatment seems to happen due to alteration of mandible posturing ${ }^{25}$, morphofunctional balance of soft tissue, muscles and occlusion ${ }^{29}$ established by the treatment and by monitoring patients with an interdisciplinary team ${ }^{28}$. Nevertheless,
TMD must not only be the object of systematic investigation, but must also indicate adequate therapeutic treatment for all the individuals who underwent combined orthodontic-surgical treatment for correction of dentofacial deformities ${ }^{30}$.

The correction of malocclusion by orthognatic surgery does not cause significant increase or decrease in signs and symptoms of $\mathrm{TMD}^{25,31}$ and the relationship among the type of malocclusion, pattern, type of orthognatic surgery and TMD is complex and not clearly established ${ }^{13}$. In fact, there are more questions than answers $^{32}$. It is important to point out that the aim of this study was not to compare the type of malocclusion, pattern or orthognathic surgery performed with the alterations in signs and symptoms of TMD, but to evaluate if these alterations remained constant or underwent significant changes over three and six months after surgery. Therefore, it was not possible to determine what type of malocclusion showed significant increase or decrease signs and symptoms of TMD.

Similarly, the data of this study were collected using Helkimo Index without using auxiliary methods of diagnosis, like radiographs and computed tomography, magnetic resonance or electromyography, and therefore it was not possible to explain whether the alterations in the signs and symptoms of TMD were related to anatomical changes that occurred in the patients. The Helkimo Index, despite being widely used, is a very limited tool to assess TMD or muscular pain ${ }^{15}$. Some authors used RDC/ TMD and noted that this research criterion may help establishing postoperative treatment plans by evaluating the patient's psychological and psychosocial state ${ }^{11,17,33}$.

Table 2 - Clinical assessment of mandibular movements according to time.

\begin{tabular}{|c|c|c|c|c|c|c|c|c|c|}
\hline \multicolumn{2}{|l|}{ Movement } & \multicolumn{2}{|c|}{ Initial (T0) } & \multicolumn{2}{|c|}{ After 3 months (T1) } & \multicolumn{2}{|c|}{ After 6 months (T2) } & \multicolumn{2}{|c|}{ Total } \\
\hline \multirow[t]{3}{*}{ Right laterality } & Canine Guidance & 0 & $(0.0)$ & 3 & $(20.0)$ & 3 & $(20.0)$ & 6 & (13.3) \\
\hline & Group function & 15 & $(100)$ & 12 & $(80.0)$ & 11 & (73.3) & 38 & (84.4) \\
\hline & N. C. Ex. & 0 & $(0.0)$ & 0 & $(0.0)$ & 1 & $(6.7)$ & 1 & (2.3) \\
\hline \multirow[t]{3}{*}{ Left laterality } & Canine Guidance & 0 & $(0.0)$ & 5 & $(33.3)$ & 6 & $(40.0)$ & 11 & $(24.4)$ \\
\hline & Group function & 14 & (93.3) & 8 & (53.4) & 9 & $(60.0)$ & 31 & (68.9) \\
\hline & N. C. Ex. & 1 & $(6.7)$ & 2 & $(13.3)$ & 0 & $(0.0)$ & 3 & (6.7) \\
\hline
\end{tabular}

Absolute frequency: outside of parenthesis/Relative Frequency: inside parenthesis.

Table 3 - Frequency of muscular pain on palpation according to time.

\begin{tabular}{|c|c|c|c|c|c|c|c|c|}
\hline \multirow{2}{*}{$\begin{array}{l}\text { Muscle } \\
\text { Masseter } \\
(p>0.05)\end{array}$} & \multirow[b]{2}{*}{ Presence } & \multicolumn{2}{|c|}{ Initial (T0) } & \multicolumn{2}{|c|}{ After 3 months (T1) } & \multicolumn{2}{|c|}{ After 6 months (T2) } & \multirow{2}{*}{$\begin{array}{c}\text { Total } \\
12(26.7)\end{array}$} \\
\hline & & 6 & $(40.0)$ & 3 & $(20.0)$ & 3 & $(20.0)$ & \\
\hline & Absence & 9 & $(60.0)$ & 12 & $(80.0)$ & 12 & $(80.0)$ & $33(73.3)$ \\
\hline & Total & 15 & $(100.0)$ & 15 & $(100.0)$ & 15 & $(100.0)$ & $45(100.0)$ \\
\hline \multirow{3}{*}{$\begin{array}{l}\text { Temporal } \\
(p>0.05)\end{array}$} & Presence & 6 & $(40.0)$ & 3 & $(20.0)$ & 1 & $(6.7)$ & $10(22.2)$ \\
\hline & Absence & 9 & $(60.0)$ & 12 & $(80.0)$ & 14 & (93.3) & $35(77.8)$ \\
\hline & Total & 15 & (100.0) & 15 & (100.0) & 15 & (100.0) & $45(100.0)$ \\
\hline \multirow{3}{*}{$\begin{array}{l}\text { Lateral Pterygoid } \\
(p<0.05)\end{array}$} & Presence & 6 & $(40.0)$ & 0 & $(0.0)$ & 0 & $(0.0)$ & $6(13.3)$ \\
\hline & Absence & 9 & $(60.0)$ & 15 & $(100.0)$ & 15 & $(100.0)$ & $39(86.7)$ \\
\hline & Total & 15 & $(100.0)$ & 15 & $(100.0)$ & 15 & $(100.0)$ & $45(100.0)$ \\
\hline \multirow{3}{*}{$\begin{array}{l}\text { Medial Pterygoid } \\
(p<0.05)\end{array}$} & Presence & 8 & $(53.3)$ & 1 & $(6.7)$ & 0 & $(0.0)$ & $9(20.0)$ \\
\hline & Absence & 7 & $(46.7)$ & 14 & $(93.3)$ & 15 & $(100.0)$ & $36(80.0)$ \\
\hline & Total & 15 & (100.0) & 15 & (100.0) & 15 & (100.0) & $45(100.0)$ \\
\hline
\end{tabular}

Absolute frequency: outside of parenthesis/Relative Frequency: inside parenthesis. 
Several orthognathic surgery procedures involve functional changes and a considerable impact on the patients' esthetic appearance. These changes provide the patients physical and psychological benefits. However, their expectations for improved esthetics may possibly be higher than the expectations of functional improvement. Patients will only be satisfied with surgical results if their expectations have been exceded. In this study, most patients subjected to orthognathic surgery reported they were satisfied with the obtained results and had self esteem improvement after surgery ${ }^{34}$, while some of them showed to be dissatisfied ${ }^{1,15}$. Dantas et al. ${ }^{1}$ (2015), observed that $97,6 \%$ of the patients were satisfied with the obtained results, presenting a psychosocial and functional improvement. Some authors related that appearance improvement is a psychological factor that leads to functional improvement ${ }^{11,17,35}$, as observed in this study.

Early rehabilitative physiotherapy could facilitate early recovery in mandibular range of motion, so it is important to emphasize the need for interaction between specialists in cases treated with orthognathic surgery, including orthodontics, oral maxillofacial surgery, physical therapy, especially in the first six months ${ }^{36}$. A jointly prepared diagnosis and treatment plan guarantee better results, but long-term follow up also contributes to psychological improvement and a better quality of life in these patients ${ }^{32}$. However, in this study, no patient had physical therapy and it was not possible to conclude that this kind of therapy could improve TMD signs and symptoms.

It was concluded that all patients showed alterations of signs and symptoms of TMD after orthognathic surgery. However, no patient presented worse symptoms. It was not possible to correlate such alterations with malocclusion correction and with the evaluated time intervals, despite the reduction in clicking, face pain and pain in masticatory muscles at the first moment (T1) after surgery, which may have occurred due to other factors, like surgical influence or psychological factors. Most patients were highly satisfied with the results obtained after orthodontic-surgical treatment. In fact, orthognathic surgery can bring beneficial effects to TMD and quality of life, but a longer follow-up study could improve the understanding of TMD in orthognathic patients.

\section{References}

1. Dantas JFC, Neto JNN, Carvalho SHG, Martins IMCLB, Souza RF, Sarmento VA. Satisfaction of skeletal Class III patients treated with different types of orthognatic surgery. Int J Oral Maxillofac Surg. 2015;44(2):195-202.

2. Baek SH, Kim TK, Kim MJ. Is there any difference in the condylar position and angulation after asymmetric mandibular setback? Oral Surg Oral Med Oral Pathol Oral Radiol Endod. 2006;101(2):155-63.

3. Rocha VAC, Trindade Neto AI, Rebello IMCR, Esteves LS, Santos $\mathrm{JN}$, Zanetta-Barbosa D, et al. Skeletal stability in orthognatic surgery: evaluation of methods of rigid internal fixation after counterclockwise rotation in patients with Class II deformities. Br J Oral Maxillofac Surg. 2015;53(8):730-5

4. Bernell-Baviera A, Bellot-Arcis C, Montiel-Company JM, AlmerichSilla JM. Effects of mandibular advancementsurgery on the temporomandibular joint and muscular and articular adaptative changes-a systematic review. Int J Oral Maxillofac Surg. 2016;45(5):54552.
5. Talentts RH, Stein S, Macher DJ, Katzberg RW, Murphy W. Predisposing and precipitating factors in temporomandibular disorders. Semin Orthod. 2012;18(1):10-29.

6. Wolford LM, Rodrigues DB, Limoeiro E. Orthognatic and TMJ surgery: postsurgical patient management. J Oral Maxillofac Surg. 2011;69(11):2893-903

7. Wolford LM, Reiche-Fischel O, Mehra P. Changes in temporomandibular joint dysfunction after orthognathic surgery. J Oral Maxillofac Surg. 2003;61(6):655-60.

8. Onizawa K, Schmelzeisen R, Vogt S. Alterations of temporomandibular joint symptoms after orthognathic surgery: comparison with heathy volunteers. J Oral Maxillofac Surg. 1995;53(2):117-21.

9. Nale JC. Orthognatic Surgery and the temporomandibular patient. Oral Maxillofac Surg Clin North Am. 2014;26(4):551-64.

10. Helkimo M. Studies on function and dysfunction of the masticatory system. Sven Tandlak Tidskr. 1974;67(2):101-21.

11. Kuhlefelt $\mathrm{M}$, Laine $\mathrm{P}$, Thorén $\mathrm{H}$. Bilateral sagittal split surgery is not a predictable treatment for temporomandibular dysfunction in patients with retrognathia. Oral Surg Oral Med Oral Pathol Oral Radiol Endod. 2016;121(6):595-601.

12. Athanasiou EA, Melsen B. Craniomandibular disfunction following surgical correction of mandibular prognatism. Angle Orthod. 1992;62(1):9-14.

13. Dervis $E$, Tuncer $E$. Long-term evaluations of temporomandibular disorders in patients undergoing orthognathic surgery compared with a control group. Oral Surg Oral Med Oral Pathol Oral Radiol Endod. 2002;94(5):554-60.

14. Landes CA, Sterz M. Proximal segment positioning in bilateral sagittal split osteotomy: intraoperative controlled positioning by a positioning splint. J Oral Maxillofac Surg. 2003;61(12):1423-31.

15. Martin MD. Orthognatic surgical treatment may produce improved temporomandibular functional status in adults with pretreatment dysfunction. J Evid- Based Dent Pract. 2011;11(4):191-3.

16. Gaggl A, Schultes G, Santler G, Karcher H, Simbrunner J. Clinical and magnetic resonance findings in the temporomandibular joints of patients before and after orthognathic surgery. Br J Oral Maxillofac Surg. 1999;37(1):41-5

17. Mladenovic I, Dodic S, Stosic S, Petrovic D, Čutovic T, Kozomara R. TMD in Class III patients reffered for orthognatic surgery: psychological and dentition-related aspects. J Cranio-Maxillofac Surg. 2014;42(8):16049.

18. Kim YK, Kim SG, Kim JH, Yun PY, Oh JS. Temporomandibular joint and psychosocial evaluation of patients after orthognatic surgery: a preliminary study. J Cranio-Maxillofac Surg. 2013;41(5):e83-6.

19. Farella M, Michelotti A, Bocchino T, Cimino R, Laino A, Steenks MH. Effects of orthognathic surgery for Class II malocclusion on signs and symptoms of temporomandibular disorders and on pressure pain thresholds of the jaw muscles. Int J Oral Maxillofac Surg. 2007;36(7):5837.

20. Flynn B, Brown DT, Lapp TH, Bussard DA, Roberts WE. A comparative study of temporomandibular symptoms following mandibular advancement by bilateral sagittal split osteotomies: Rigid versus nonrigid fixation. Oral Surg Oral Med Oral Pathol. 1990;70(3):372-80.

21. Trauner R, Obwegwser $\mathrm{HL}$. The surgical correction of mandibular prognathism and retrognathia with consideration of genioplasty. Part I. Oral Surg. 1957;10(7):677-89

22. Epker BN. Modification in the sagittal osteotomy of the mandible. J Oral Surg. 1977;35:157-9.

23. Sartoretto $S C$, Bello YD, Bona AD. [Evidências científicas para 0 diagnostico e tratamento da DTM e a relação da oclusão e a orthodontia]. RFO 2012;17(3):352-9. Portuguese.

24. Al-Belasy F, Tosoglu S, Dolwick MF. Mandibular hipomobility after orthognatic surgery: a review article. J Oral Maxillofac Surg. 2013;71(11):1967.e1-1967.e11. 
25. Rodrigues-Garcia RCM, Sakai S, Rugh JD, Hatch JP, Tiner BD, Sickels JE, et al. Effects of major Class II occlusal corrections on temporomandibular signs and symptoms. J Orofac Pain. 1998;12(3):18592.

26. Abrahamsson C, Henrikson T, Nilner M, Sunzel B, Bondmark L, Eckberg EC. TMD before and after correction of dentofacial deformities by orthodontic and orthognatic treatment. Int J Oral Maxillofac Surg. 2013;42(6):752-8.

27. Al-Ryiami S, Cunningham S, Moles DR. Orthognatic treatment and temporomandibular disorders: a systematic review. Part 2. Signs and symptoms and meta-analyses. Am J Orthod Dentofacial Orthop. 2009;136(5):626.e1-626.e16.

28. Silva MMA, Ferreira AT, Migliorucci RR, Nari Filho H, Berretin-Felix G. Influence of orthodontic-surgical treatment on signs and symptoms of temporomandibular dysfunction in subjects with dentofacial deformities. Rev Soc Bras Fonoaudiol. 2011;16(1):80-4.

29. Togashi M, Kobayashi T, Hasebe D, Funayama A, Mikami T, Saito I, et al. Effects of surgical orthodontic treatment for dentofacial deformities on signs and symptoms of temporomandibular joint. J Oral Maxillofac Surg Med Pathol. 2013;25(1):18-23.

30. Cascone P, Paolo C, Leonardi R, Pedullà E. Temporomandibular disorders and orthognathic surgery. J Craniofac Surg. 2008;19(3):687-92.
31. Lindenmeyer A, Eghtessad M, Goulden R, Speculand B, Harrys M. Oral and maxillofacial surgery and chronic painful temporomandibular disorders - a systematic review. J Oral Maxillofac Surg. 2010;68(11):275564.

32. Nadeshah M, Mehra P. Orthognatic surgery in presence of temporomandibular dysfunction. What happens next? Oral Maxillofac Surg Clin North Am. 2015;27(1):11-26.

33. Kim YK, Kim SG, Kim JH, Yun PY. Clinical survey of the patients with temporomandibular joint desorders using research diagnostic criteria (axis II) for TMD: preliminary study. J Cranio-Maxillofac Surg. 2012;40(4):366-72.

34. Guimarães Fo. R, Oliveira Jr. EC, Gomes TRM, Souza TDA. [Quality of life in patients submitted to orthognatic surgery: oral health and selfsteem]. Psicol Cienc Prof. 2014;34(1):242-51. Portuguese.

35. Silvola A S, Tolvanen M, Rusanen J, Sipila K, Lahti S, Pirttiniemi $P$. Do changes in oral health-related quality-of-life, facial pain and temporomandibular disorders correlate after treatment of severe malocclusion. Acta Odontol Scand. 2016;74(1):44-50.

36. Teng TT, Ko EW, Huang CS, Chen YR. The effect of early physiotherapy on the recovery of mandibular function after orthognatic surgery for Class III correction: part I - jaw motion analysis. J Cranio-Maxillofac Surg. 2015;43(1):131-7. 